\title{
O LUGAR DO EXÍLIO: memória a (re)cobrar
}

Sonia Torres

As demandas da representação de identidades, na contemporaneidade, encontram-se centradas em dois eixos aparentemente paradoxais. São esses eixos a memória e o deslocamento. Em sua coleção de ensaios publicada no Brasil, Seduz̨idos pela memória, Andreas Huyssen discute o privilégio que temos dado à memória, em especial, a memória coletiva e política traumática -, o que tem gerado uma produção cultural que narra o que ele denomina "passados presentes" da pós-modernidade, em oposição aos "futuros presentes" da modernidade (Huyssen, 2000). Os discursos atuais da memória surgem, em grande medida, como conseqüência de eventos políticos nacionais ocorridos no século 20 que, por sua vez, levaram à diáspora (o paradigma é o Holocausto, mas incluem-se na mesma categoria o fenômeno da descolonização e o exílio, em conseqüência das ditaduras). "O foco contemporâneo na memória e na temporalidade", escreve Huyssen, "contrasta totalmente com muitos outros trabalhos inovadores sobre categorias de espaço, mapas, geografias, fronteiras, rotas de comércio, migrações, deslocamentos e diásporas” (Huyssen, 2000: 9). Se, como argumenta Huyssen, o lugar politico das práticas de memória é ainda nacional, e não pósnacional ou global (Huyssen, 2000:17 - ênfase do autor), e se, por outro lado, tais práticas são freqüentemente desenvolvidas a partir de locais distintos dos eventos originais, tempo e espaço ficam entreligados de formas cada vez mais complexas, 
gerando um "movimento transnacional dos discursos de memória” (Huyssen, 2000:13). Esse movimento pode ser constatado, em especial, nas literaturas de migrantes ou exilados políticos, a partir da década de 1980.

No Canadá - e, mais especificamente, no Quebec - nos últimos vinte ou trinta anos, modificou-se o perfil dos imigrantes que aí se instalaram. Como nos demais países da América, as primeiras ondas migratórias eram provenientes de países europeus; mas, a partir dos anos 70, o Canadá passou a receber imigrantes pós-coloniais francófonos das Antilhas, Ásia e África, acarretando mudanças no panorama social quebequense. Até os anos 60, falava-se de homogeneidade em se tratando do Quebec, visão difundida pelas elites no século XIX, que não correspondia necessariamente à experiência vivida no cotidiano, mas que fazia parte do imaginário de tais elites. Tal homogeneidade se baseava na crença da mono-identidade minoritária do Canadá, fundamentada na defesa da língua francesa e da religião católica, alicerces que permitiam o reconhecimento da cultura nacional e a ocultação das divisões e conflitos de uma sociedade em vias de industrialização. Com a chegada de novas levas de imigrantes oriundos de países não europeus, o caráter heterogêneo da cultura quebequense se tornou cada vez mais visível (cf. Porto \& Torres, 2005). E se, anteriormente, obras literárias colocavam em relevo a figura de imigrantes, o que é novo, a partir dos anos 80, é o reconhecimento, por parte da crítica, da pluralidade cultural da escrita quebequense, ou, como esclarece Pierre Nepveu, dá-se a tomada de consciência da multiplicidade de centros de referência identitária no âmbito da literatura produzida no Quebec (cf. Nepveu, 1988).

No início dos anos 70, como parte da onda migratória desencadeada pelos golpes de estado no Cone Sul, o Canadá passou a ser a nação anfitriã de um grande número de imigrantes latino-americanos, sobretudo de indivíduos provenientes do Chile (mas também da Argentina e do Uruguai). De maneira semelhante ao que ocorreu nos EUA - que hoje contam com mais de 40 milhões de falantes do espanhol -, a chegada contínua de imigrantes da América Latina, durante o último quarto do século passado, tem sido responsável pela produção literária de hispano-americanos em solo canadense. Embora a comunidade hispânica dos EUA ultrapasse a população total do Canadá, um número crescente de escritores hispânicos passa a fazer parte das literaturas anglófonas e francófonas do último, diretamente, ou através de traduções para o inglês e francês.

Fica caracterizada, portanto, a diferença apontada por Graciela Montaldo, entre o ideário do século 19, cuja imaginação territorial foi responsável pela construção de um território "real", que expande e define os limites da nação ao definir seus mapas, 
e os "espaços virtuais" da nação, construídos nos interstícios pelas mais recentes gerações de exilados (cf. Montaldo, 1999). Se, como escreveu Amin Maalouf, o país que acolhe o imigrante não é nem uma página branca, nem uma página pronta, é uma página que está sendo escrita (Maalouf, 1998), tal país é, ao mesmo tempo, repositório de grande parte tanto da história política recente da nação de origem quanto da memória do emigrado ou exilado.

O que me traz ao foco central deste trabalho - e ao 11 de setembro. Trata-se, contudo, de outro 11 de setembro, aquele que ficou gravado para sempre na história do Chile: 11 de setembro de 1973, quando as forças armadas, encabeçadas pelo general Augusto Pinochet deram o golpe que acabaria com a institucionalidade democrática do país. O resultado foi uma dispersão global de exilados chilenos, e o surgimento de uma literatura chilena da diáspora, em que tais autores examinam a distância imposta pelo exílio. Essa geração diaspórica incluía inúmeros jovens autores, recém ingressados na carreira literária. Forçados a afastar-se de sua pátria e separados de suas famílias, não surpreende que esses autores tematizem em suas obras o período de ditadura na América Latina, e o subseqüente exílio. $O$ exílio significa não somente separação do país de origem: ele é marcado por lembranças de violências física e psicológica, carreiras interrompidas, identidades nacionais truncadas e pela necessidade de adaptar-se a novos lugares.

Ao chegar ao Canadá, os escritores chilenos logo trataram de se organizar em torno de grupos de leitura e de revistas imprimidas artesanalmente. Em Ottawa, para onde migraram vários jovens filiados a movimentos de vanguarda, como a Escola de Santiago, logo se formou um núcleo de produção literária chilena, e foi estabelecida a primeira editora latino-americana do Canadá, a Cordillera, co-fundada por Leandro Urbina ${ }^{1}$, cujo romance Cobro revertido (chamada a cobrar) passarei a discutir. ${ }^{2}$

Nascido em 1948, Leandro Urbina pertence à geração cuja experiência coletiva sofreu uma ruptura repentina, com o regime militar (1972-1989) de Augusto Pinochet. Nascido em Santiago do Chile, Urbina exilou-se em 1974. Ele reside no Canadá desde 1977, onde, além de escrever, dá aulas na universidade, é tradutor, diretor de cinema e jornalista. Além de Cobro revertido - pelo qual ganhou o Prêmio do Conselho Nacional do Livro e da Leitura do Chile, em 1993, tendo também se destacado entre os finalistas do Prêmio Planeta argentino - Urbina publicou a coleção de contos Las malas juntas (2000).

A experiência narrada em Cobro revertido é um inventário da vida do protagonista. A mola-propulsora da narrativa, e que irá deslanchar a seqüência de recordações do protagonista, desde a infância até seu exílio em Montreal, é um telefonema, infor- 
mando a morte de sua mãe, que "morreu com seu nome nos lábios" (Urbina, 1999:19). A ação, no território presente (cuja narração corresponde a um dia), gira em torno de sua decisão de ir ao enterro da mãe - mesmo considerando o risco que terá de correr, dadas suas atividades junto ao Movimento Estudantil no passado, e embora seu tio recomende prudência, porque “a situação em Santiago não estava boa, eles andaram invadindo as favelas" (Urbina, 1999:19).

A narrativa assume uma forma de delírio, em que memória e espaço presente encontram-se entretecidos, e são representados pela oscilação do foco narrativo, ora na terceira pessoa (presente), ora na primeira pessoa (passado), nos remetendo para a definição de Iain Chambers do estrangeiro: "Vir de outro lugar, de "lá" e não "daqui", e estar, então, simultaneamente "dentro" e "fora" [...] é viver nas interseções de histórias e memórias" (Chambers, 1994: 6).

Podemos relacionar o "dentro" e o "fora" de que fala Chambers, por sua vez, ao exílio externo e interno dos expatriados. Em sua análise de Maldición eterna a quien lea estas páginas, de Manuel Puig, Guillermina Rosencrantz refere-se ao "deambular pelos lugares escondidos da memória" como uma experiência dialógica que permite reconstruir a identidade dos exilados, um interno e outro externo. Ela define a produção dos novos espaços imaginários como uma forma de liberdade criativa. Frente à perda da intimidade com os espaços "reais" de outrora, e à falta de intimidade com os novos espaços heterotópicos, ocorre uma "desarticulação dos pontos de referência de identidade", levando a uma ruptura no processo identificatório que liga o corpo ao território e o território ao corpo (Rosencrantz, 1999: 54). Os condenados à heterotopia vêem-se, assim, levados a construir seu sentimento de pertença não mais vinculado à intimidade do espaço territorial, mas ao espaço da memória e da imaginação.

A justaposição entre presente/passado é representada, no romance de Urbina, por seus encontros com o círculo de amigos chilenos exilados do protagonista, que também "sofrem” de memória, e decidem ajudá-lo a preparar-se para a viagem à terra natal. Tais preparativos consistem, ao fim e ao cabo, em fazer uma vaquinha para comprar-lhe um novo terno em um "brechó" da vizinhança e envolver-se em debates sobre os mais variados assuntos, sempre regados a doses abundantes de álcool. Sua entrada em um bar, onde encontra os amigos, marca o nível presente e "real" da narrativa; mas durante as infindáveis discussões do grupo, o protagonista deixa seu pensamento vagar de volta ao passado, lembrando de sua mãe, para, então, incorporar-se novamente ao presente. Individualmente, cada membro do grupo é estereotipado pelo Sociólogo, que, colocando-se como o estranho, o "de fora" de que fala Chambers, descreve Tito e Toño Guzmán como "gordos grandalhões e bigodudos, 
com pinta de caminhoneiros e vestindo elegantes jaquetas de tweed acadêmico"; Moisés García é o "velho senhor todo arrumadinho, que parece um funcionário dos correios"; Sarita é a "magrela, sem sombra de dúvida professora primária"; quanto a Antônio Gamboa e seu filho, ele descreve como "bem penteados contadores públicos, com óculos de fundo de garrafa"; e Frías como um "tipo cadavérico, professor de filosofia" (Urbina, 1999: 44).

A postura distante e analítica do protagonista aponta para a função paródica do grupo, na medida em que seus integrantes servem de estratégia para o escritor, através de seu alter-ego, o Sociólogo, "fazer uma vistoria (crítica) da reserva de imagens do passado" (Hutcheon, 1989: 93). Se, por um lado, Frías declara "Somos a memória coletiva. Vocês todos... são a água que mata a sede de minha nostalgia" (Urbina, 1999: 55); por outro, o distanciamento irônico do protagonista parece ser uma estratégia sua para evitar sucumbir à nostalgia. O mesmo personagem, Frías, é quem observa que "[n]o exílio vivemos incestuosamente" (Urbina, 1999: 21), acabando por confirmar a análise que o Sociólogo faz da família estendida, que compartilha seu sentimento de alienação e incerteza sobre o futuro. São todos "[e]xilados, refugiados, desintegrados, deslocados, desorientados, perdidos no espaço, felizes, infelizes, patéticos. Sua tribo, sua gente, para melhor e para pior, orgulhosa, arrogante e chorona, sua quase-família desde o começo, agora para sempre.”(Urbina, 1999: 44)

As observações sobre as relações incestuosas da família estendida no exílio lembram a observação da protagonista de outro romance sobre a experiência no exílio, Memory mambo, da cubana Achy Obejas:

tenho só vinte-e-quatro anos, e muitas vezes me pergunto se minhas lembranças são tão claras. Às vezes fico convencida de que elas são recordações de outra pessoa que eu absorvi. (...) Às vezes me pergunto se a gente não passa tempo demais juntos, dia após dia, trabalhando e comendo lado a lado, dormindo nos mesmos cômodos, fundindo nossos sonhos. Às vezes me pergunto se sabemos onde cada um de nós termina e onde os outros começam. (Obejas, 1996: 9)

Em sua discussão sobre as literaturas dos desterritorializados, Emily Hicks aponta para a tendência à tomada de uma "decisão consciente de aceitar a desterritorialização e de resistir às tentações da nostalgia" (Hicks, 1991: 116). A tensão entre esses dois movimentos é tematizada através da oscilação do protagonista entre passado/presente, e por sua tentativa de distanciar-se da nostalgia compartilhada. Por outro lado, o incesto ou (con)fusão das histórias pessoais de cada membro da "família" de exilados forma, ao mesmo tempo, uma história coletiva de desenraizamento, de deslocamento. 
Isso explica por quê, a partir do telefonema, Frías e os demais exilados de Cobro revertido passam a viver, vicariamente, através do Sociólogo, o sonho do retorno.

Entre os temas abordados nos debates surgidos a partir do pós-estruturalismo e pós-modernismo, a relação entre história e ficção tem recebido atenção especial. Ao construir um texto híbrido, contendo diversas formas de representação e diferentes estratégias textuais, que justapõe recordações pessoas e questões públicas, Urbina combina o elemento imaginativo com a narração de uma história coletiva maior. $\mathrm{O}$ escritor argentino Marcelo Cohen chama a atenção para a necessidade premente do expatriado de reorganizar um espaço próprio. Tal necessidade leva-o a construir um "cenário de [...] experiência, entendendo-se por esta o produto do vivido, mas também do que se pensa, se sonha, se imagina e se sente" (in Saavedra,1993:85-87). Nesse sentido, Cobro revertido é um exercício do processo de recriação da memória que se compõe através do entrecruzamento de um conjunto complexo de fatos históricos e fatores sociais, que se alimenta, ao mesmo tempo, de um Carnaval de sonhos, memórias, reflexões.

As recordações do narrador estão centradas, primordialmente, em quatro figuras femininas: a mãe, María Serrano; a primeira namorada, Magdalena; a ex-mulher anglo-canadense, Megan; e a atual amante, a quebequense Marcia. As quatro personagens, com exceção de Marcia, correspondem a diferentes momentos no passado do protagonista, e também a passagens da história do Chile e do Canadá, pois é através da narração de suas relações com essas mulheres que irão surgir os temas mais propriamente políticos e sociais do romance de Urbina. As recordações do personagem sobre a mãe (que é simpatizante do golpe de 1973) encontram-se repletas de ressentimento e acusações, uma vez que o protagonista a culpa pelo desaparecimento da namorada nos porões da ditadura. Assim, para o Sociólogo, a morte de ambas está para sempre ligada à disjunção nacional; ao passo que Megan e Marcia estão estreitamente ligadas à disjunção entre presente e passado, representando o Canadá anglófono e o francófono, respectivamente, e seus temores de perder a identidade chilena, uma vez que, quando elas surgem em seus sonhos e devaneios, tais momentos estão marcados por fantasias de perda da identidade chilena - como o pesadelo contendo a imagem de Megan enterrando-o vivo nas areias de uma praia do Chile; ou quando ele contempla casar-se com Marcia e tornar-se membro da família Vauquelin, porque "se Quebec vai tornar-se independente, vai precisar de cidadãos para amar e respeitá-la, não é verdade?” (Urbina, 1999:187).

Em relação a esta última referência, cabe ressaltar a contextualização da história canadense recente: a narrativa está entremeada de referências ao movimento sepa- 
ratista do Quebec, liderada por René Levesque, tema constante de debates acalorados entre os membros do grupo de amigos expatriados do Sociólogo. Através dessa estratégia narrativa, Urbina nos informa a respeito de como os exilados políticos do Canadá mostraram-se divididos sobre o referendum franco-canadense, pois muitos, com medo da deportação, preferiram não tomar partido. Se, por um lado, Frías reflete filosoficamente que "somos ingênuos, não enxergamos para além da projeção de nossas próprias ansiedades de singularidade", o Sociólogo prefere acreditar que "não estamos equivocados. Não estaremos condenados a sermos uma turma de espécimes irrelevantes" (Urbina, 1999: 57). No ensaio "Mutações e (i)migrações no espaço quebequense", Maria Bernadette Porto discute o caráter plural de impossibilidades do ser migrante; entre elas, a impossibilidade de chegar, de se tornar quebequense, de traduzir a língua do outro, ou seus próprios desejos e sentimentos (Porto, 2000). Assim, a identificação dos personagens chilenos exilados com outra cultura minoritária, a quebecois, é apenas mais uma impossibilidade, entre tantas outras, já que a desterritorialização os situa, sempre, no espaço entre duas culturas e, portanto, duas memórias culturais, condenando-os, perpetuamente, ao exílio interno.

O romance termina com uma cena de Carnaval de rua. O Sociólogo está em busca de Marcia, mas encontra, ao invés, uma mulher de cerca de quarenta anos de idade (coincidentemente, a idade que teria Magdalena, sua namorada desaparecida durante a luta armada), "uma vaga réplica de Carmem Miranda", que, apesar dos trajes chamativos, "dançava com uma graça e energia que davam gosto" e falava francês com um "sotaque estranho" (Urbina, 1999:189-190). O protagonista acaba envolvendo-se em uma briga com o marido ciumento de sua parceira de dança, e acaba sendo apunhalado por um membro do grupo que a acompanha. O Sociólogo tomba, "ao rugido de uma onda" (Urbina, 1999: 191). "Sem o consolo da morte heróica imaginada mais de mil vezes" o Sociólogo dedica sua última onda de memórias a Magdalena, e

esse último gesto dos dedos que tocam o céu proletário, esse último grito que seus companheiros de combate recordariam para sempre, que os lindos lábios das moças de sua terra repetiriam para sempre. Tanto sonho épico, tantas histórias de heroísmo que deram em nada, e tanta amargura trivial, e tanta tentativa de não naufragar, tudo para acabar aqui, no Parc Lafontaine, acompanhado desse calipso medíocre e desafinado, aos pés suarentos do mundo, em Montreal, como um inseto esmagado, Megan. Seria hilariante demais. (Urbina, 1999:193) 
A ironia da cena final está no fato de o protagonista não perceber que a figura vestida de Carmem Miranda, assim como toda sua entourage, é chilena. As ironias embutidas no texto são responsáveis, em grande medida, pelo clima alucinatório, em crescendo, da narrativa de Urbina, confirmando as palavras de Amy Kaminsky, de que o exílio é uma forma particular de presença-na-ausência (Kaminsky, 1993: 29). Kaminsky observa, ainda, como a linguagem demonstra ter o exílio localidade própria: as pessoas vivendo fora de seus países estão "no exílio". Não constitui surpresa, portanto, o fato de o lugar físico do exílio ser percebido como um não-país, e não um outro país. Neste sentido, o exílio é definido "pelo que está faltando, não pelo que ele contém” (Kaminsky, 1993: 30):

Havia momentos em que se sentia desorientado e não sabia onde estava ou o que estava fazendo nesta cidade, e ele ouvia pessoas falando e parecia que estavam falando espanhol e ele pensava às vezes que talvez fosse só uma questão de dobrar uma esquina e ele se encontraria em frente à sua casa em Santiago e abriria a porta, iria para seu quarto e deitaria, finalmente, e dormiria em sua própria cama, para descansar sem preocupações e acordaria quando sua mãe o chamasse para jantar... (Urbina, 1999: 186)

A forma narrativa empregada por Urbina parece indagar a todo o tempo "como narrar o presente se há um passado a recobrar"? Ao mesmo tempo, ecoa as palavras de Andreas Huyssen de que "assegurar o passado não é uma tarefa menos arriscada do que assegurar o futuro" (Huyssen, 2000: 36).

\section{$\operatorname{son}$}

\section{NOTAS}

1 Entre os co-fundadores da Cordillera estão Jorge Etcheverry e Naín Nómez. A editora publicou a antologia bilíngüe Literatura chilena en Canadá/Chilean Literature in Canada (1982). Toronto, que teve algumas publicações mais difusas, foi estabelecendo-se, pouco a pouco, como centro dessa nova literatura. Em 1987, o jornalista e crítico peruano Alex Zisman organizou uma espécie de mega-festival, o "Encuentro Norte-Sur", na Universidade de York, que tinha como finalidade reunir autores anglo e franco canadenses com escritores hispânicos da América Latina e do Canadá. Nessa mesma época, surgiu a Agrupación de Artistas Latinoamericanos, uma associação de escritores, músicos, pintores, cineastas, atores, bailarinos e artistas performáticos, que apresentaram vários festivais; e, alguns anos depois, Mario Valdés e Margarita Feliciano, entre outros, inauguraram a Semana del Idioma Español, cujas atividades seguem acontecendo anualmente, desde 1991 - sendo atualmente o maior evento em espanhol do Canadá. Devo essas informações, assim como o breve panorama das letras hispânicas no Canadá incluídas neste trabalho, ao meu colega Hugh Hazelton, da Concordia University. cf. sua palestra "Una literatura nueva: la 
latinocanadense", Concordia University, 18 de fevereiro de 2004. O texto, na íntegra, encontra-se disponível online: http://artsandscience.concordia.ca/cmll/spanish/antonio/Conferencias_03-04.html.

2 Todas as citações no corpo do texto, com tradução minha para o português, foram retiradas da edição canadense, traduzida para o inglês como Collect call (1999), com o número da página indicada parenteticamente. Original em espanhol de 1992.

\section{REFERÊNCIAS}

CHAMBERS, Iain. Migrancy, Culture, Identity. New York \& London: Routledge, 1994.

HICKS, Emily. Border writing: the multidimensional text. Minneapolis \& Oxford: University of Minneapolis Press, 1991.

HUTCHEON, Linda. "The politics of parody". In —. The politics of postmodernity. London \& New York: Routledge, 1989.

HUYSSEN, Andreas. Seduridospela memória. Trad. Sergio Alcides. Rio de Janeiro: Aeroplano/MAM, 2000. KAMINSKY, Amy. Reading the body politics: feminist criticism and Latin American women writers. Minneapolis \& London: University of Minnesota Press, 1993.

MAALOUF, Amin. Les identités meurtrières. Paris: Bernard Grasset, 1998.

MONTALDO, Graciela. Ficciones culturales y fábulas de identidad en América Latina. Rosario: Beatriz Viterbo, 1999.

OBEJAS, Achy. Memory mambo. Pittsburgh \& San Francisco: Cleis Press, 1996.

PORTO, Maria Bernadette \& TORRES, Sonia. "Literaturas Migrantes". In Itinerários Transculturais, org. Euridice Figueiredo. Niterói \& Juiz de Fora: EDUFF e Editora da UFJF (no prelo).

PORTO, M.B. "Mutações e (i)migrações no espaço quebequense”. In ——, org. Fronteiras, passagens, paisagens na literatura canadense. Niterói: EdUFF; ABECAN, 2000, pp. 49-80.

NEPVEU, P. et al. L'écologie du réel: mort et naissance de la littérature québécoise contemporaine. Montréal: Boréal, 1988.

ROSENCRANTZ, Guillermina. El cuerpo indómito: espacios del exilio en la literatura de Manuel Puig. Buenos Aires: Ediciones Simurg, 1999.

SAAVEDRA, Guillermo. La curiosidad impertinente. Entrevistas con narradores argentinos. Rosario: Beatriz Viterbo, 1993.

URBINA, Leandro. Collect call. Trad. Beverly J. DeLong-Tonelli. Ottawa: Split Quotation, 1999. Original em espanhol: Cobro revertido. Santiago: Planeta, 1992

URBINA, L. Las malas juntas. Madrid: Editorial AKAL, 2000.

\section{Resumo}

Este trabalho examina representações identitárias e políticas no romance Cobro revertido, do chileno José Leandro Urbina. A experiência narrativa de Urbina organiza um espaço de escrita e reflexão que invoca o político através da memória e da prática concreta de desterritorialização, de distanciamento de si próprio, afirmando a emergência dos "passados presentes" da pósmodernidade, em oposição aos "futuros presentes" da modernidade (Huyssen, 2000), representados no texto pela experiência da disjunção nacional e temporal. 


\section{Abstract}

This work examines identitary and political representations in José Leandro Urbina's Collect call. The author's narrative experience organizes a space of writing and reflection that invokes the political through both memory and concrete practices of deterritorialization, of distancing from oneself, affirming the shift from the "present futures" of Modernity to the "present pasts" of Postmodernity (Huyssen, 2000), represented in the text through the experience of national and temporal disjuncture.

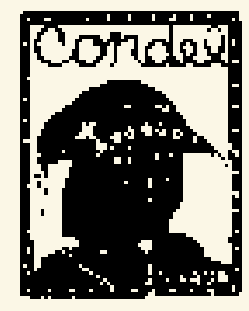

Sonia Torres é Professora Adjunta da UFF. Graduada em Letras pela PUC-RJ, Mestre em Literaturas de Língua Inglesa e Doutora em Literatura Comparada pela UFRJ, Pós-Doutorado na UNIRIO e no Programa Avançado de Cultura Contemporânea/ PACC,UFRJ, Rockefeller Fellow e Professora Visitante da University of Iowa. É co-Editora Executiva da revista Transit Circle. Foi Presidente da Associação Brasileira de Estudos Americanos/ABEA (1999-2001) e Vice-Presidente da International American Studies Association/IASA (2000-2003). É autora do livro Nosotros in USA (2001) e organizadora da coletânea interdisciplinar Raízes e rumos (2001). 